\title{
Midface Lift: Our Current Approaches
}

\author{
Verjüngung des Mittelgesichts: Aktuelle Ansätze
}

\author{
Authors \\ G. Botti, C. Botti \\ Affiliation \\ Plastic Surgery, Villa Bella Clinic, Saló, Italy
}

\section{Key words \\ - midface lift \\ - tissue filling \\ $\checkmark$ ageing \\ plastic surgery}

Schlüsselwörter

- Mittelgesichtsstraffung

- Gewebeunterspritzung

- Alterung

- Plastische Chirurgie received 23.07.2014

accepted 23.07.2014

\section{Bibliography}

DOI http://dx.doi.org/

10.1055/s-0034-1385927

Handchir Mikrochir Plast Chir

2014; 46: 224-233

(c) Georg Thieme Verlag KG

Stuttgart · New York

ISSN 0722-1819

Correspondence

Dr. Giovanni Botti, MD

Plastic Surgery

Villa Bella Clinic

Europa 55

25087 Saló

Italy

Tel.: + 39/0365/41446

Fax: + 39/0365/524 231

botti@villabella.it

\section{Abstract \\ $\nabla$}

In the last few years, surgery of the ageing face seems to have shifted from tissue uplifting and tightening to mere filling. We do not agree with this trend. We are positive that ageing brings about 2 basic phenomena: on one hand bone and fat volume reduction, whilst on the other a deterioration of the skin lining (elastosis) leading to an increase in its compliance and extension. We therefore deem of the utmost importance to couple soft tissue filling with indispensable tightening and repositioning together with resection of overabundant skin. For what concerns the midface area in particular, we suggest to resort to 3 different lifting techniques, according to the kind of defect to be treated. It is important to take the right pulling vector into consideration as well as the need of skin excess removal. The procedures can be tailored to suit any peculiar need such as malar bag, lower lid border malposition, tear trough deformity, etc. Different cases will be taken into consideration as examples of the various indications and techniques.

\section{Introduction \\ $\nabla$}

A wrong idea is spreading among plastic surgeons all over the world. Some researchers are suggesting that ageing changes are essentially related to fat atrophy and propose to treat every defect just with fat grafting or fillers. This is simply false. In fact ageing generally entails changes of skin texture (atrophy, elastosis, etc.), which give rise to its relaxation and "enlargement", as well as modifications of the inner tissues (fat and bone atrophy, fat ptosis, loss of muscular and fas-

\section{Zusammenfassung}

In der Chirurgie des alternden Gesichts wurde in den letzten Jahren zunehmend statt Gewebeanhebung und Gewebestraffung lediglich die Gewebeunterspritzung durchgeführt. Die Autoren unterstützen diesen Trend nicht. Wir sind vielmehr der Ansicht, dass Alterung 2 grundlegende Phänomene mit sich bringt: einerseits eine Reduktion des Knochen- und Fettvolumens, andererseits eine Verschlechterung des elastischen Eigenschaften der Haut, was zu höherer Dehnbarkeit und Dehnung führt. Wir sind daher überzeugt, dass die Unterspritzung von Weichgewebe im Gesicht generell mit der dafür erforderlichen Straffung und Neupositionierung mit einer Resektion der überschüssigen Haut gekoppelt werden sollte. Insbesondere in Bezug auf den Mittelgesichtsbereich schlagen wir, je nach zu behandelndem Problem, 3 verschiedene Lifting-Techniken vor. Entscheidend sind sowohl die richtigen Zugvektoren als auch die Notwendigkeit einer Entfernung der überschüssigen Haut zu berücksichtigen. Die Verfahren können auf spezielle Bedürfnisse angepasst werden, wie im Bereich des Jochbeins, Unterlidfehlstellung, Tränensackdeformation usw.

Für die jeweiligen Indikationen und Techniken werden in dieser Übersichtsarbeit beispielhaft verschiedene Fälle vorgestellt.

cial tone, etc.), with a consequent reduction of their volume and loss of projection and support to the overlying lower lid. This gap between the container and the content is one of the most important reasons of the ageing-related aesthetic problems. Any experienced surgeon knows that in the vast majority of cases it is impossible to obtain natural and long-lasting results without removing skin excess. This is the main reason why the so-called thread-based treatments (insertion in the fat of barbed sutures, which are supposed to lift the soft tissues without any skin 

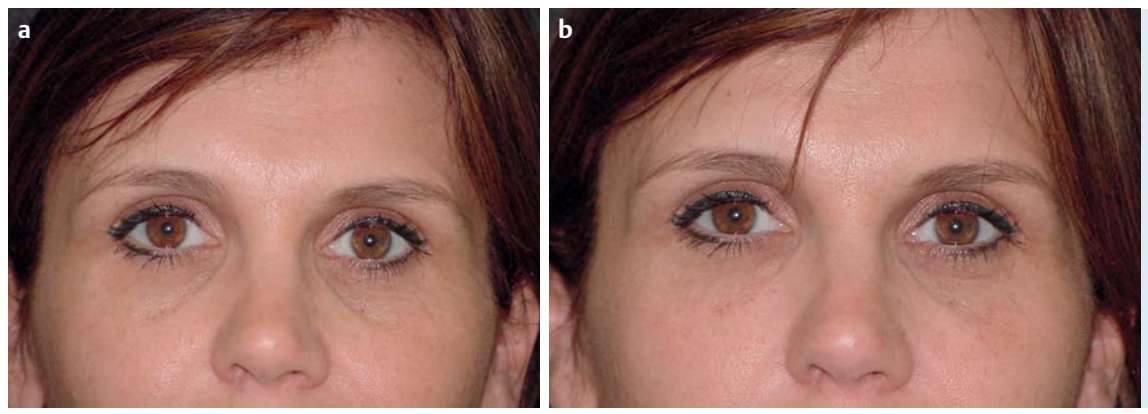

Fig. 1 a, b Hyaluronic acid injections. When the aesthetic defect is limited to a tear trough without any soft tissue laxity one can resort to hyaluronic acid injection with concrete but short-lasting results. In this case a non-hydrophilic hyaluronic acid should be preferred in order to prevent excessive swelling of the treated area.

a Ageing-related changes in face and neck

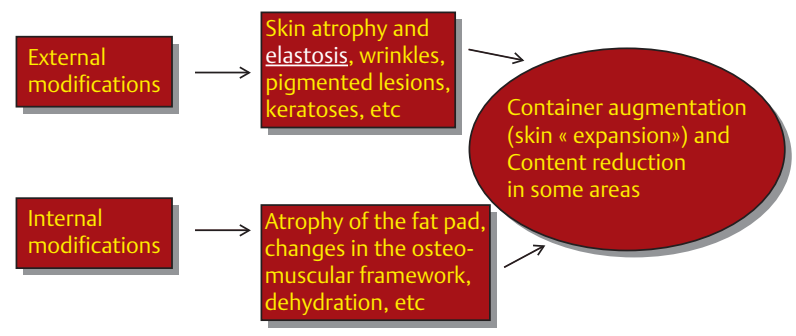

b

$$
\text { Ageing-related changes in face and neck }
$$

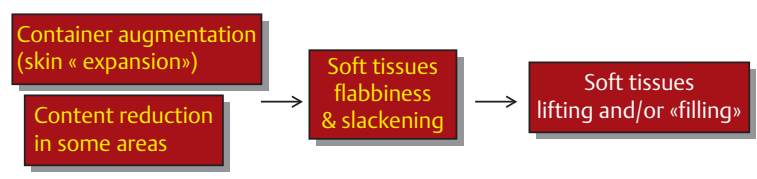

Fig. 2 a, b Flowchart for the treatment of midface-ageing related defects. If these problems are related to both ptosis and deflation, we should try to lift and fill soft tissues. Quite often though, lax soft tissue reposition alone is sufficient to allow great and stable results. That is a "pure" midface lift.

removal) fail to correct ageing problems in the face. The same unnatural and ineffective outcomes can be often observed after the injection of overabundant quantities of various substances (fat, hyaluronic acid, etc.) in the attempt not only to integrate the soft and hard tissue atrophy, but also to fill the enlarged skin, which should have been instead partially removed.

We have to face 2 main problems, skin "expansion" and fat/bone atrophy, and consequently, in order to obtain the best outcomes we should try to solve or, at least, to improve both of them. All these considerations are particularly valid for the midface area, where quite often the simple "filling", that nowadays seems to be the overwhelming fashion, gives a funny appearance or, in the worst cases, a monstrous look to the unlucky patient. Only in those cases where inner atrophy is prevalent, one should try to resort to "filling" only. Fat grafting, implants, hyaluronic acid injections alone can be really effective when dealing just with a well delimited local defect, like a deep tear trough or lack of cheek bone projection, but if relevant skin excess is detected, the surgeon should take into consideration also a midface lift procedure, to be performed in the same time with augmentation or alone ( $\bullet$ Fig. 1).
In the last 30 years a palette of new treatments has been proposed to improve the midface area. Some of them attracted at the beginning a lot of enthusiasm but, unfortunately, with time their use and overuse entailed terrible complications. Among them, for example, are the so-called "permanent" fillers. At the beginning they have been proposed and used by eminent plastic surgeons (in Italy, our country, they were supported by almost all plastic surgery school directors), but quite shortly they gave rise to very bad problems, often almost impossible to solve completely, as we all know. In the 1990s the removal of Bichat's fat bag through an intra-oral approach was introduced as the best option to enhance cheekbone projection and was carried out by the most "advanced" surgeons. 10-15 years later many of those poor patients had to come back to the operating room in order fill emptied cheeks with fat grafting. Extended lower blepharoplasties with sub-orbicularis dissection and muscular suspension seemed to be the best solution for malar festoons, but in many cases they provoked very annoying complications (scleral show, ectropion, etc.), until a better comprehension of the lid suspension system was reached. Nowadays, the new fashion is to treat midface defects just with fat grafting, following some debatable pathophysiological findings, which would have been demonstrating that no sagging and downwards shifting of soft tissues really takes place. We completely disagree and are deeply convinced that in order to correctly solve the ageing-related aesthetic defects of the midface area with natural and harmonious results, a more comprehensive and complete approach should be considered. First, an "unconditioned" diagnosis should be carried out and then the consequent logical treatment should be performed. Only in a few patients should midface defects be corrected by fat grafting or midface lift alone, while in the majority of cases both procedures in variable degrees should be used (๑ Fig. 2).

\section{History}

In the 1980s plastic surgeons were already able to consistently improve ageing-related defects in the lower part of the face and in the neck, but could not yet obtain any concrete improvement of midface problems. In fact at that time it was quite common to find in scientific publications post-operative pictures with disharmonious outcomes: well treated lower face, neck and even forehead and undertreated infra-palpebral and malar areas. Realizing that midface enhancement techniques were actually lacking, a few surgeons around the world tried to engage a fight against malar bags, tear throughs, "flatness under the eyes", etc.; in other words to act against midface defects.

My personal war began in the late 1980s. Disappointed with the outcomes of many inferior blepharoplasties performed to treat lower lid and extraorbital defects, following De La Plaza, 

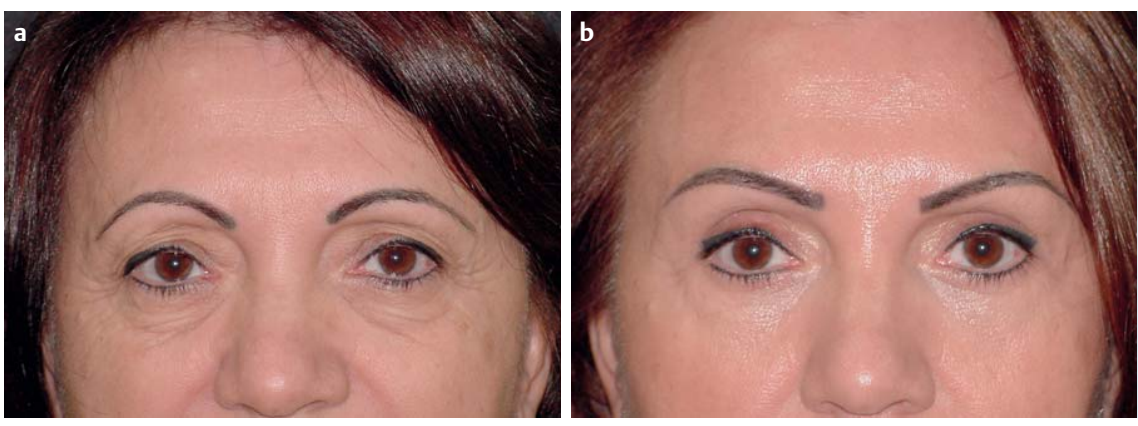

Fig. 3 a, b Extended lower blepharoplasty. If the patient's request is limited to skin excess removal and soft tissues are still in their correct position, an extended blepharoplasty with deep and superficial canthoplasty can often be sufficient to adequately fix the situation. The patient must be aware that no change in the shape of the midface area will be obtained.
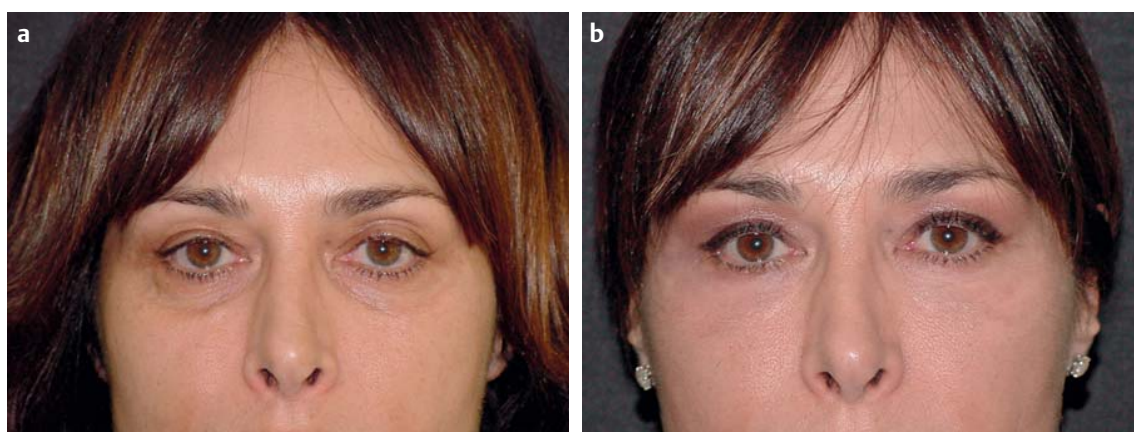

Fig. 4 a, b Fat grafting. When the patient complains of empty lower lids with deep palpebrojugal groove, the surgeon could take into consideration fat grafting. The main drawback of this operation is it longevity. In fact, even if some cases are followed by permanent results, in other cases the fat taking rate is quite low and the operation needs be carried out many times in order to get long-lasting outcomes.
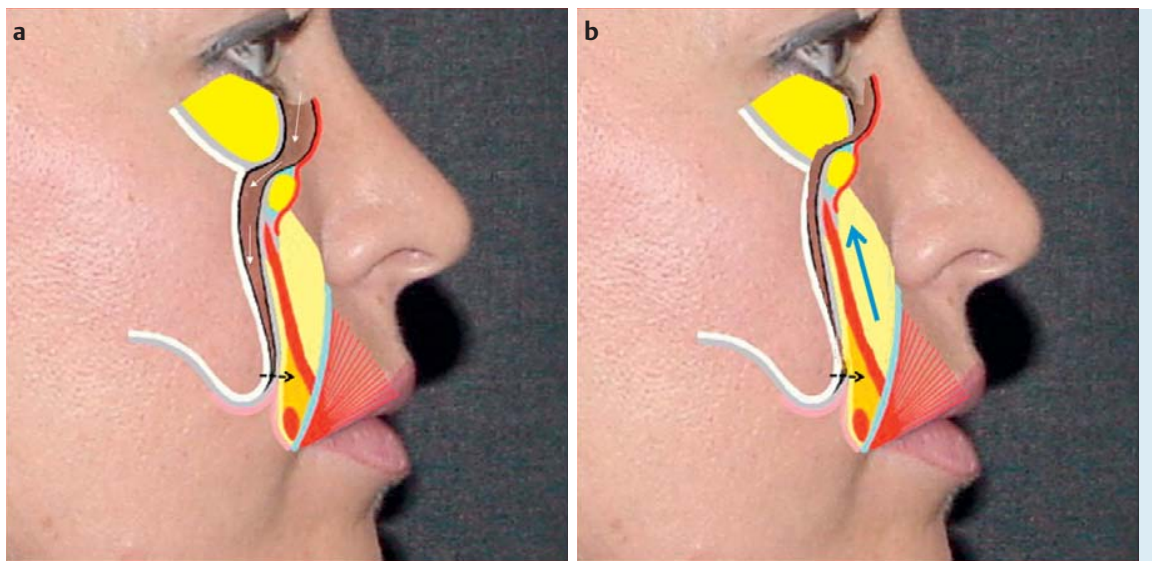

Fig. 5 a, b Sub-periosteal dissection. In the left image, the downwards extension of sub-periosteal dissection is illustrated, together with the lower section of the periosteum, that will allow one to lift the flap. In the right image, the soft tissues have been moved upward, thus filling the nasojugal groove, correcting any festoon that may be present and adding volume to the cheek bone area.

Hinderer and Faivre, first I tried extending the usual palpebral undermining downwards outside the orbital rim, in order to lift that specific area. That widened dissection was performed between the fat pad behind the orbicularis muscle (the so-called "SOOF") and the periosteum, at a level that many years later B. Mendelson called the "pre-zygomatic space". Sometimes this wide deep dissection and sagging soft tissue reposition allowed us to obtain quite good results, but in the majority of cases they were not long-lasting and a few of them were followed by complications such as ectropion and scleral show. The main problem was the instability of the fixation. Actually, even if any incidental hypotone was corrected by deep and superficial canthopexy, sometimes the lower lid border still had a tendency to move downwards. Moreover, that technique did not allow us to fill any deep palpebro-jugal groove with a thick layer of soft tissue as it would have been often necessary. But in selected cases it proved to be an effective operation, for example, to treat festoons due mainly to skin and/or muscle laxity. When both festoons and deep tear troughs were present, I used to couple this extended blepharoplasty (superficial midface lift) with dermal-fatty grafts or with the Flowers's implants placed over the orbital rim. When instead the problem was represented just by deep tear troughs without any skin-muscle sagging, my favorite treatment was fat grafting only with no undermining, that in the many cases allowed us to obtain good results, even if not always predictable. At that time, exactly as nowadays, the major drawback of this approach rested indeed in its uncertainty ( $\bullet$ Fig. 3,4$)$.

In the late 1990's I started to carry out the midface lift with a sub-periosteal dissection, as was proposed by Tessier and Krastinova and popularized by Psillakis, Little, Ramirez, Besins et al. and I immediately realized that that kind of operation had much more potential advantages if compared to the midface lift with more superficial undermining. The sub-periosteal dissection, followed by the release of the flap and its fixation to solid anchoring points, assures a more secure and stable reposition of the sagging midface soft tissues. In fact the periosteum underneath the flap strongly sticks in the new position to the local non-dissected periosteum. Furthermore a thicker layer of soft tissues can be lifted and used to fill deep palpebro-jugal grooves. This deep undermining is still the base of my midface lift, even if with time I better realized that only an individualized treatment, based on a very meticulous care of any detail, would have allowed me to obtain almost constantly great improvements over the most common defects of this area. Among the most common auxiliary procedures I couple to midface lift are obviously fat grafting and canthopexy ( $\bullet$ Fig. 5). 


\section{The Main Midface Problems}

\section{$\nabla$}

The majority of midface defects are age-related, even if sometimes we have to deal with congenital problems, like negative vector (when the eyes are more prominent than the malar soft tissues) or deep tear troughs. Actually these last particular kind of deformities can be congenital or acquired, but in both cases generally a midface lift can help to improve the situation. Further defects of this area are festoons, too high and/or sunken lower lids, too evident lid-cheek transition area, wrinkles, discoloration and some midface-related problems in the lids, like scleral show and ectropion. For what concerns these last defects, the skin gathered in the lid, lifting the midface, is generally quite helpful to substitute the lacking one, even if in these case also adjunctive procedures should often be taken into consideration.

\section{Basic Techniques for Midface Lifting}

$\nabla$

Sub-periosteal dissection is relatively easy to perform, is almost bloodless, allows us to avoid any injury to the facial nerve branches and guarantees much longer-lasting results than the supra-periosteal one. In order to carry out a complete sub-periosteal undermining of the midface area, the easiest and most comfortable access to the deep plane is undoubtedly a para-canthal stab incision, prolonged with a sub-ciliar extension when it is evident that it will be also necessary to remove a strip of excessive skin from the lower lid. Another useful approach is represented by a trans-oral incision, carried out perpendicularly to the vestibular fornix. One could pass through a temporal scalp incision as well, or even through the usual pre-auricular facelift approach, deepening the dissection at the lateral border of the malar bone. Resorting to 2 concomitant approaches enables sometimes a more precise undermining and an easier and faster operation. The dissection should be carried out both in the malar and maxillary sub-palpebral areas and should be extended above and below the infra-orbital bundle. It is important to completely release the periosteum, which is rigid and inextensible, at the periphery of the dissected zone: at the base of the malar area, along the oral upper fornix and at the level of the orbital rim. This will allow us to easily move the midface flap upwards. In this area soft tissues can be lifted along different vectors, the main ones being supero-lateral and supero-medial. These 2 pulling directions give rise to different effects. A supero-lateral vector of pull allows us to better correct malar soft tissue mounding and festoons. Furthermore an improved cheek bone projection can be obtained thanks to a deep periosteal plication. A supero-medial vector of pull is more effective when the main issue is the correction of a deep tear trough. The midface flap can be fixed to the periosteum of the periorbital rim or, better, directly to the bone at the same level through drill holes. Another solid anchoring tissue is the deep temporal fascia (the muscular aponeurosis), but this can be reached only by means of long "suspender" sutures.

\section{Analyzing Different Operations to Treat Midface Aesthetic Defects \\ $\nabla$}

As already mentioned, several operations have been proposed to correct midface problems. The 2 main procedures are based on different levels of dissection: a more superficial and a deeper one.
The technique based on superficial dissection usually starts with a sub-ciliary incision, followed by a subcutaneous dissection and by the incision of the orbicularis muscle below the lower tarsal margin. Then a palpebral myocutaneous flap is lifted reaching the lower orbital rim. At this point the undermining is extended caudally passing between the SOOF (sub-orbicularis-oculi-fat) and the periosteum and then further downwards behind the lower extension of the orbicularis muscle and the anterior cheek fat pad, but in front of the lip elevator muscles. This dissection can reach medially the naso-labial fold, but should be interrupted laterally half way to the malar bone, in order to avoid severing a branch of the facial nerve directed to the orbicularis $m$., which runs above the zygomaticus major muscle. The flap thus obtained is lifted and fixed with a few sutures to the periosteum of the lower orbital rim. When necessary, i.e., in case of lower lid hypotone, deep and/or superficial canthopexy is also carried out. Finally skin excess is removed and the wound is sutured.

The deep (sub-periosteal) dissection is used in 3 main different procedures. 2 are based on a supero-lateral vector of pull, 1 on a supero-medial vector of pull.

The first type of midface lift with sub-periosteal dissection is a “closed approach" procedure, actually performed through only 3 small stab incisions. The first is in the scalp of the temporal area, about $1.5 \mathrm{~cm}$ behind the hairline. Through this approach a tunnel is created between the superficial and the deep temporal fascia. This dissection is extended sub-periosteally in the forehead and both the insertions of the frontal periosteum and of the superficial temporal fascia along the supero-lateral orbital rim are disrupted and completely released. The second incision is traced lateral to the lateral canthus (as the usual extension of the lower blepharoplasty incision). Through it, the sub-periostal undermining of the malar and maxillary areas is performed. Care should be taken to avoid any damage to the infra-orbital bundle, even if the dissection should be extended below and above it in order to move soft tissues from the midface area to the lid. The zygomaticus-facial bundle instead is usually sectioned without any relevant change in local sensitivity. A third incision is carried out in the mouth, perpendicular to the vestibular fornix. This last incision will allow us to complete and verify the midface dissection and to insert a Reverdin needle, used to anchor the wide flap. The needle is passed through the buccal incision and the dissected midface area and exits from the para-canthal incision. Then a thread is mounted on its eye, the needle pierces the flap and exits again from the para-canthal incision. Now the suture is withdrawn from the needle and its 2 extremities are passed through the temporal tunnel, pulled and fixed to the deep temporal fascia (muscular aponeurosis) under appropriate tension. A second similar fixation, with a suture pulled along a slightly different vector, is often carried out. The operation is completed with a couple of sutures between the superficial and deep temporal fasciae with the aim of lifting the para-canthal soft tissues and the eyebrow tail.

The second operation based on a sub-periosteal dissection is substantially similar to the first one, but in this case the paracanthal incision is extended underneath the lashes till the medial canthus and through this approach the anchorage is easily executed with no need of any supplementary oral incision. So after the scalp incision and temporal undermining are carried out, this sub-ciliar incision is performed and through it the malar/maxillary undermining. Then through this same incision the midface flap is directly anchored (with no need of any Reverdin needle) with a long "suspender" suture, that is fixed to the 

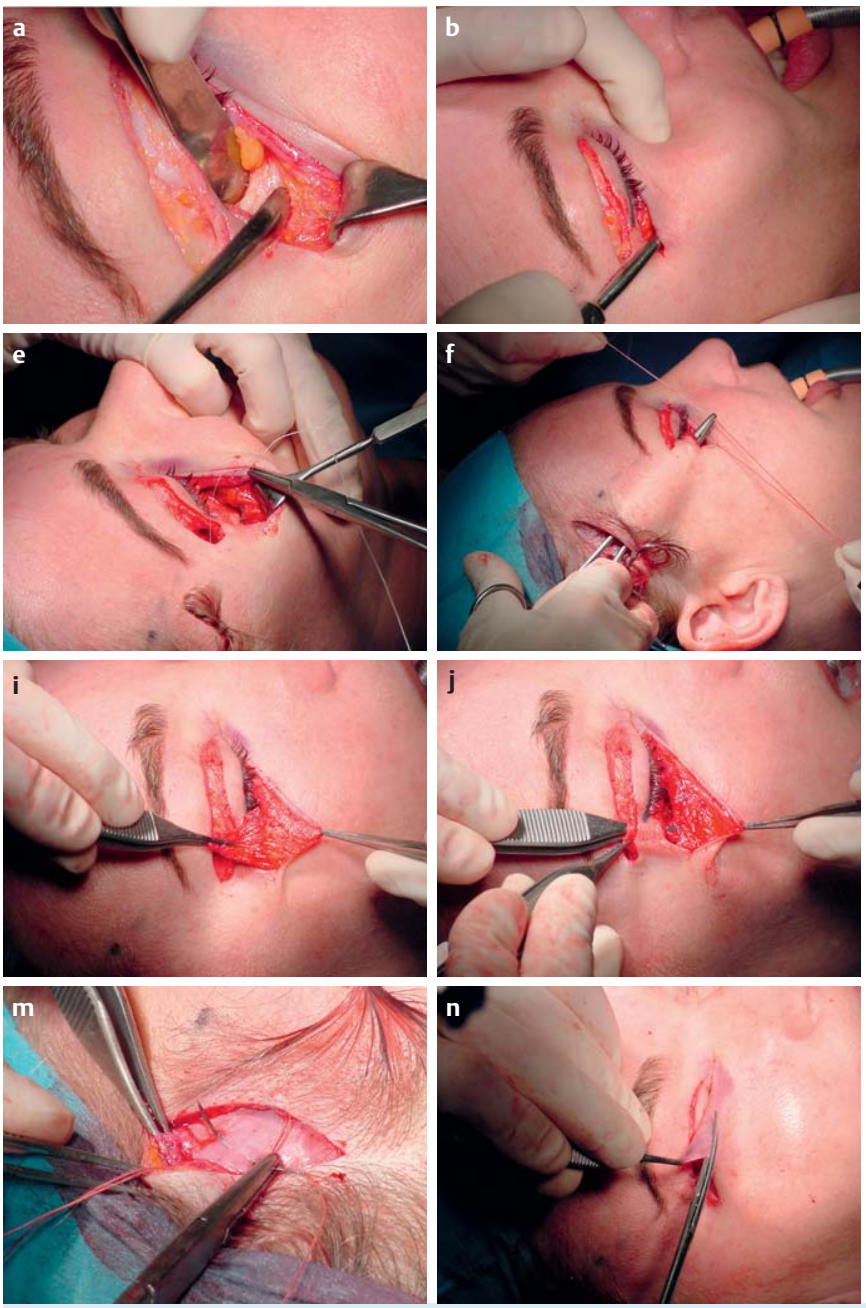

Fig. 6 a-d "Suspender" midface lift: sugical technique. On the left, the orbital rim periosteum is reached and the sub-periosteal dissection is started; in the second image it is extended to the malar and maxillary areas, where a fingertip protects the infra-orbital bundle. In the third figure, a sub-fascial tunnel is created, connecting the temporal scalp incision to the midface. In the last image the temporal undermining is extended sub-periosteally to the forehead, paying attention to avoid any damage to the supra-orbital bundle. $\mathbf{e - h}$ "Suspender" midface lift: surgical technique. On the left the flap is hooked with a 3/0 Vicryl suture; in the second picture the suture is grasped with a needle holder and passed through the temporal tunnel. In the third image the upper extremity of the long suture ("suspender")

deep temporal fascia. The upper margin of the orbicularis muscle flap is also fixed to the periosteum of the supero-lateral orbital rim through the para-canthal tunnel. The most important difference between the first and the second type of midface lift with sub-periosteal dissection is that this last one allows the removal of potential excessive skin at the level of the sub-ciliar incision. If the lower lid suspension system (canthal tendoncanthal ligament-orbicularis muscle) is not adequately strong and tight, then a "deep" canthopexy must also be performed. In that case the surgeon should take care of anchoring the orbicularis muscle outside the orbital rim and the canthal ligament and/or tendon inside, in order to avoid any detachment of the lower lid from the eye globe ( $\bullet$ Fig. 6 ).

The third operation based on a sub-periosteal dissection has a different vector of traction. While the first 2 procedures rely on a superior-lateral pull, this last one entails a superior-medial vector. With this technique there is no need of buccal, or temporal
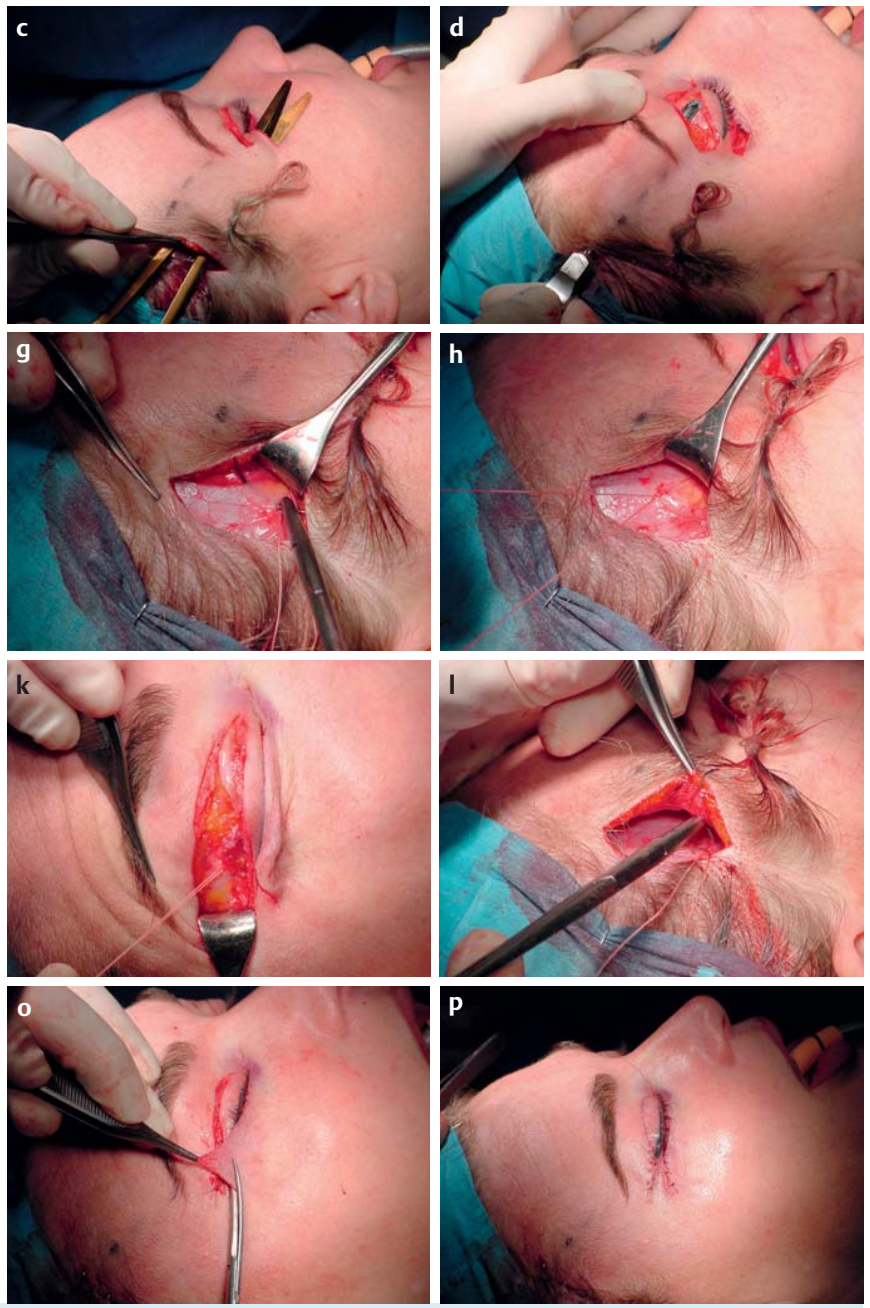

pierces the deep temporal fascia and in the last picture it is tightened. i-I "Suspender" midface lift: sugical technique. The first image shows the creation of an orbicularis flap, that is passed through a paracanthl tunnel (second picture) and fixed to the periosteum of the lateral orbital rim and to the deep temporal fascia (third image). In the last picture the temporal flap is grasped by a Vicryl 3/o suture. m-p "Suspender" midface lift: sugical technique. The same suture pierces also the deep temporal fascia (left picture) and, when pulled and tightened, lifts the eye brow tail. In the second and third images a strip of excessive skin is conservatively removed along the sub-ciliary incision. The last picture shows the final sutures.

incisions because it is completely performed through the lids. The operation starts with a small incision in the lateral part of the upper lid groove extended for a few mm externally to the orbital rim or instead, when needed, with the usual upper blepharoplasty skin removal. Then a para-canthal incision with a sub-ciliar extension (as in any lower blepharoplasty) is carried out. Sub-periosteal dissection is performed in the malar/maxillary area as with the other techniques, but in this case is extended to the inner side of the inferior and supero-lateral orbital rim. Then 2-3 drill holes are created in the bone along the inferior orbital margin and one on its supero-lateral part. The midface flap is grasped with a suture under direct vision about $1 \mathrm{~cm}$ inferiorly and laterally to each drill hole and then the same suture is passed through the respective hole. By tying the sutures the midface flap is lifted and fixed in its new position. An orbicularis flap is sculptured in the sub-canthal portion of the muscle (Adamson's flap) and is passed through the para-canthal 

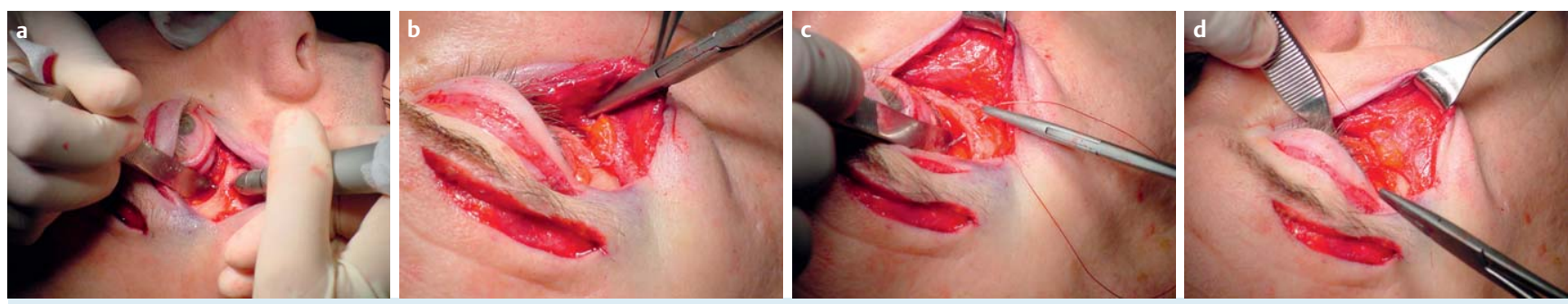

Fig. 7 a-d "Belt" midface lift: surgical technique. In the first image a drill hole is created in the orbital rim; then the flap is hooked with a suture needle (2nd picture), that afterwards passes through the bony perforation ( $3^{\text {rd }}$ picture). Finally the suture is knotted (last image). This lifting maneuver allows to reposition the SOOF (sub orbicularis oculi fat) on the orbital rim, as is clearly visible in the illustrations, thus filling the palpebro-jugal groove.

tunnel and anchored to the upper drill hole. In the majority of the cases a canthopexy is also carried out, taking care of passing its retaining suture from inside to outside the orbital rim. This last maneuver can be facilitated if also along the supero-lateral orbital rim 2 drill holes are created. Frequently large quantities of skin can be removed at the end of this operation but, as in any procedure involving lower lid dissection, care should be taken in leaving at least $3 \mathrm{~mm}$ of apparently excessive skin in order to prevent lid margin displacement due to inner scar retraction. The usual suture completes surgery. We prefer soft 5.0 silk single stiches in order to avoid that the thread extremities inadvertently scratch the cornea in the post-operative period ( $\bullet$ Fig. 7 ).

\section{Indication for Midface Lift Procedures with Sub-Periosteal Dissection}

$\nabla$

Technique no. 1 ("closed approach" without subciliary incision) should be used when there is no extra skin to resect in the lower lid. Best candidates are younger patients, whose desire is just a better definition and shape of the midface area.

Technique no. 2 (with complete sub-ciliary incision, orbicularis flap and temporal fixation) should be chosen when there is skin excess to remove in the lower lid, if a superior-lateral traction vector is needed (to be discussed with the patient in front of a mirror) and when cheekbone projection must be improved.

Technique no. 3 (purely trans-palpebral, with orbital rim drill holes) should be preferred when a superior-medial traction vector is needed, if a temporal incision should be avoided (bald men) and when the main issue is the correction of a deep tear trough. In fact it allows us to better elevate the most medial midface soft tissues, thus covering the exposed lower orbital rim, caused by anterior cheek fat pad and SOOF ptosis ( $\bullet$ Fig. 8-10).

\section{Other Techniques used to Correct Midface Aesthetic Defects \\ $\nabla$}

In some particular cases fat grafting can be considered a valid alternative to midface lift. Best indications for "lipofilling" or "lipostructure" (nowadays in the common surgical language these 2 nouns are almost considered as synonymous) are those patients who show mainly lack of soft and/or hard tissue thickness. Very often ageing entails atrophy of both fat and bone and, even if less frequently, this can also be a congenital characteristic. Very rarely laxity that develops with the ageing process is totally due to fat depletion and/or bone atrophy because a very important role is played by skin thinning and enlargement. Beyond face and neck, this same phenomenon is easily detecta- ble in almost any other area of the body, even if it is more evident in specific zones such as inner and anterior/posterior side of thighs, arms, abdomen and breast. In other words, as already mentioned, 2 different phenomena take place: from one side the extension of skin surface (the container) increases, and from the other side fat and bone volume (the content) decreases. But in selected cases fat grafting (or HA injections/implants) alone offers very good outcomes, while in other cases these procedures should be coupled with a midface lift or, at least, with a regular lower face and neck lift (better, in that case, if resorting to the high-SMAS technique) ( $\bullet$ Fig. 11).

\section{Drawbacks of Various Procedures}

\section{$\nabla$}

The main specific complication of midface lift is lower lid displacement. It could seem to be weird because this operation is frequently carried out with the aim of correcting scleral show and ectropion, thanks to the large quantity of skin that can be recruited. Nevertheless, if not correctly executed, it could be the cause of such defects. At the beginning there is a steep learning curve and a very important rule any surgeon should fix in mind from the outset is to leave, at the end of the operation, at least $3 \mathrm{~mm}$ of extra skin. This is very important in order to compensate for post-operative scar retraction, which always takes place, especially if first a skin flap was lifted. In order to avoid lower lid displacement, it is also fundamental to detect and correct any hypotone of the suspension system during the operation and to avoid any blood collection. Another possible complication of sub-periosteal midface lift consists in an unnatural result, which is more frequent if a canthopexy is associated. This is surgeondependent and for sure, experience helps a lot to get a better appreciation of different vectors and strengths of pull and to obtain a well-balanced and natural outcome.

For what concerns fat grafting, the most frequent complication is its reabsorption, as well as the opposite, meaning too much fat taking. Generally it is common practice to slightly overcorrect the defects because some adipose tissue will certainly die and will be eliminated by the body. Nevertheless not rarely fat can be found in excess after surgery on the tear through (and sometimes even on the zygoma) and should be removed. In order to prevent this annoying complication, along the orbital rim fat should always be injected deeply, behind the orbicularis muscle, while only very tiny quantities (drops) could be positioned directly under the skin. Unfortunately there is no special technique which can always guarantee fat taking. One can choose different harvesting areas, resort to various treatments, such as filtration, decantation, centrifugation or use special devices or even follow particular procedures (fat condensation, ADSC 

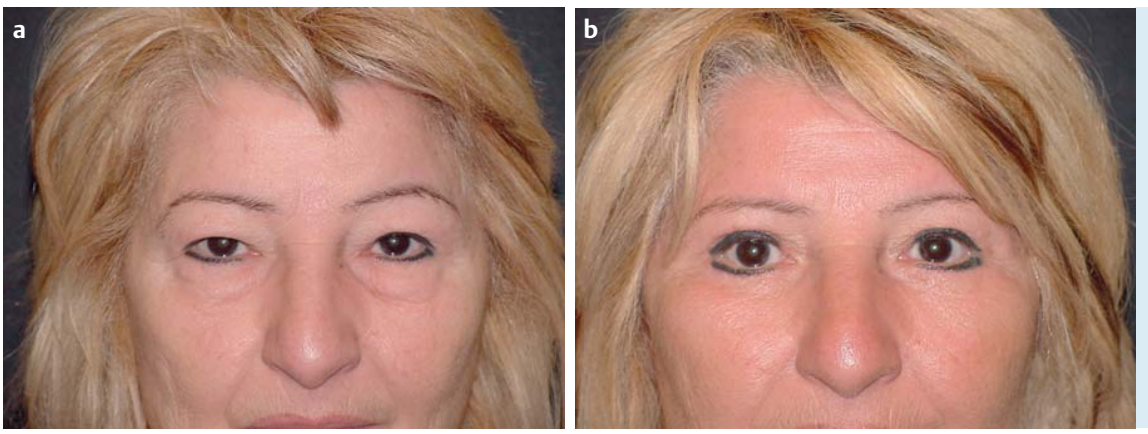

Fig. 8 a, b Basic midface lift. Upper lid dermatochalasis and lower lid fat bags are quite evident in this patient, as well as soft tissue ptosis in the midface. A good correction cannot be obtained with fat grafting, which would be responsible only of more heaviness in the orbital/periorbital area. Instead soft tissue repositioning allowed one to fix those problems with very natural results. To be noticed is that no fat was removed in the lower lid because fat herniations (fat bags) were pushed back in their original position by midface and orbicularis tightening.
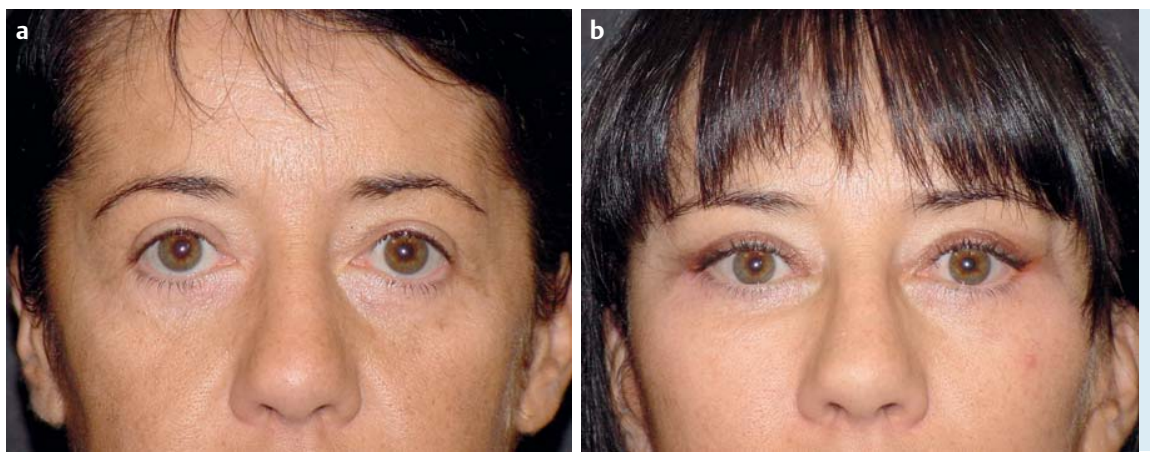

Fig. 9 a, b Scleral show corrected by midface lift and canthoplasty. An overzealous blepharoplasty produced these round eyes (left picture). The great quantity of skin moved upwards from the midface area allowed us to fill the gap (scleral show) between the lower limbus (inferior margin of the pupil) and the lower lid margin.
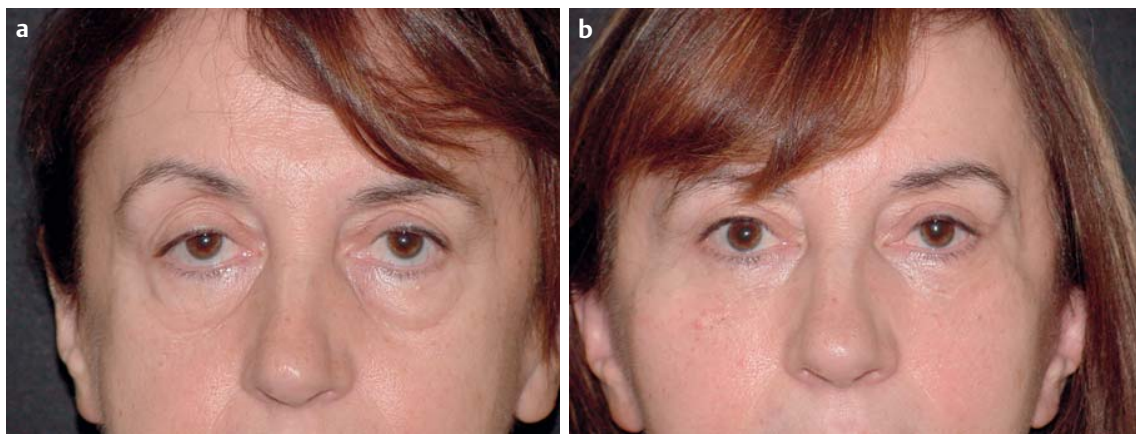

Fig. 10 a, b Senile soft tissue ptosis and scleral show. This case was treated with midface lift associated with canthopexy, fat grafting in both the upper lids and ptosis correction in the right lid. No fat was injected in the lower lid, or in the cheek bone area.
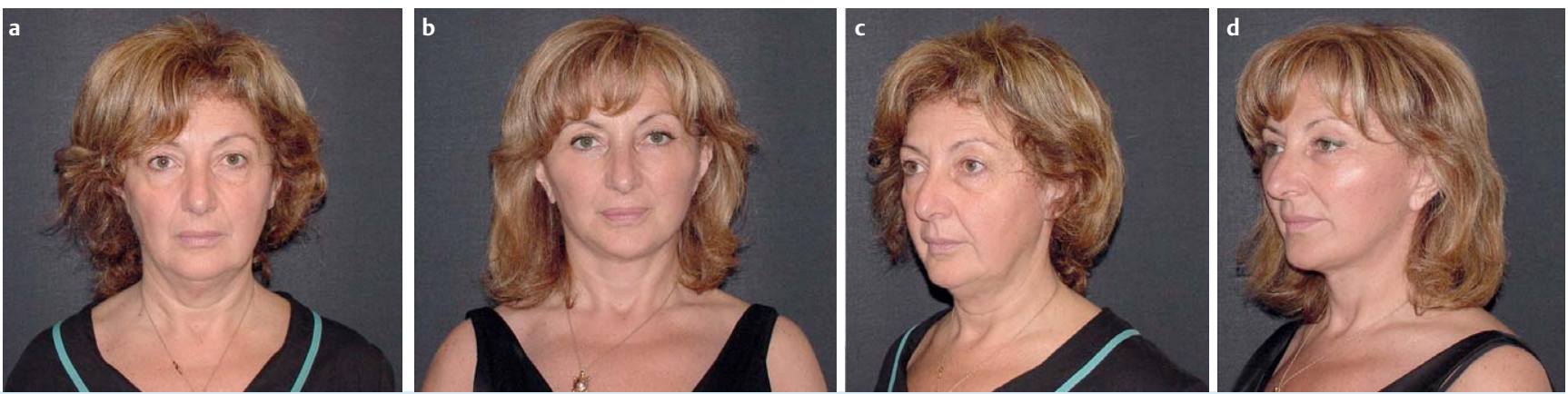

Fig. 11 a-d Midface, lower face and neck lift. This patient had soft tissue ptosis on both face and neck. In such a case we did not even consider fat grafting, that would overload her general appearance, instead we performed a regular cervico-facial lift coupled with a midface lift. The latter allowed us to correct the deep palpebro-jugal groove and to enhance the projection of the cheekbones.

enrichment, etc.), but even in the best hands the fat taking rate so far is still unpredictable. We noticed that fat has the tendency to survive more in some areas than in other ones and fortunately the midface is pretty favorable. Perhaps the use of cannulas with small holes for harvesting and injecting fat helps to get more stable results but, even following any advanced rule, fat can still partially diminish or completely disappear, and the patient should be warned about it.

Hyaluronic acid has a granted "complication": its reabsorption. The midface is relatively immobile and here hyaluronic acid per- haps lasts a bit more than in other more mobile areas. Nevertheless, it should be imprudent to guarantee that the correction obtained would last for more than one year. Another possible complication is the so-called Tyndall effect, which is a bluish discoloration due to localized swelling when hydrophilic HA is injected at the level of the tear trough. In order to solve this particular problem, hyaluronidasis should be infiltrated in the affected area. For what concerns facial implant complications, we should mention dislocation, that is pretty rare if the pocket is 

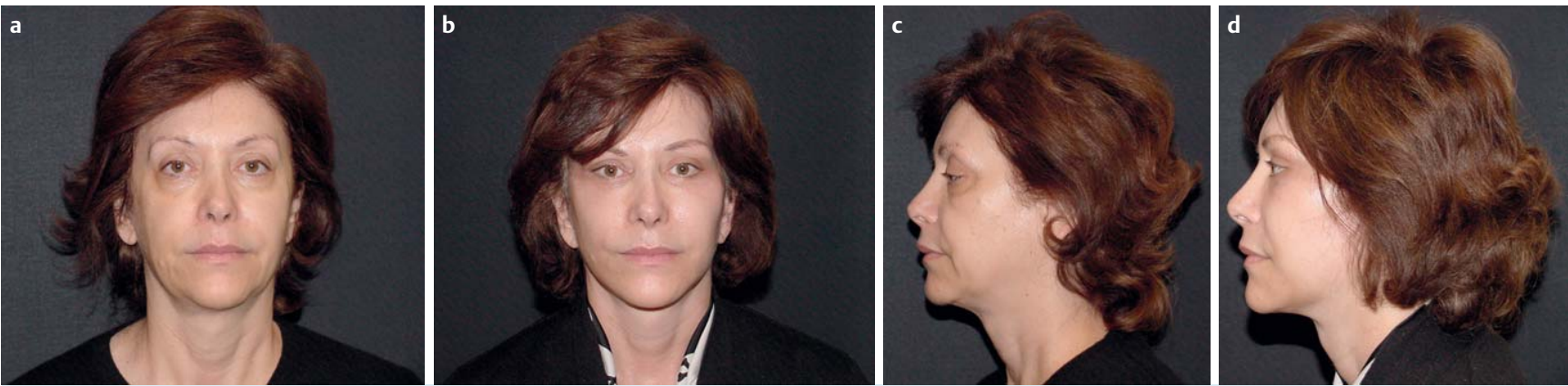

Fig. 12 a-d Midface lift and cervico-facial lift. In order to obtain a more harmonious outcome, a complete lift was performed in this case, treating midface, lower face and neck. Due to lower lid suspension system weakness, it was necessary to resort also to a canthopexy, that conferred to this patient a slightly unnatural look.
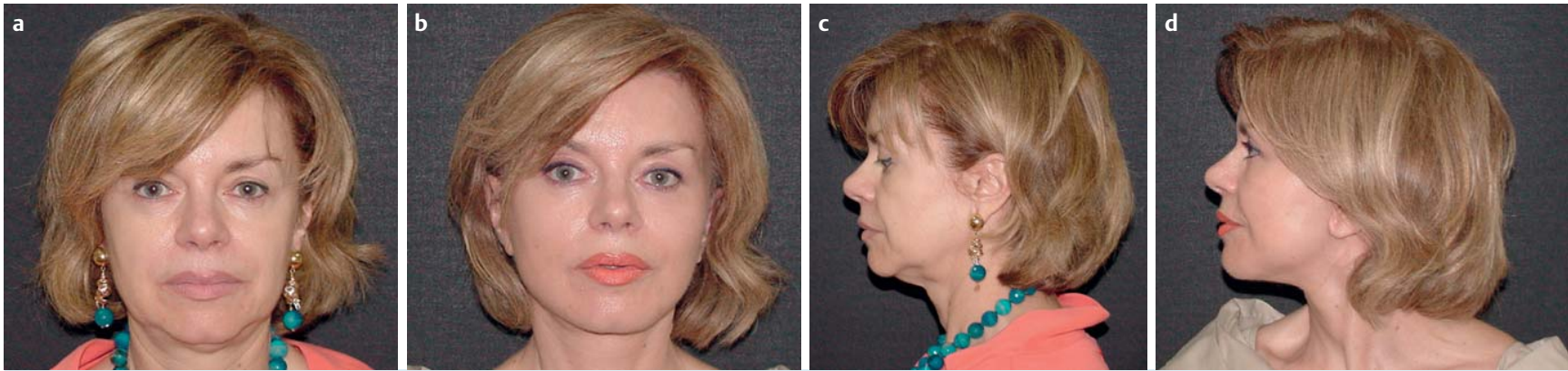

Fig. 13 a-d Midface, lower face and neck lift. This 58-year-old woman complained of an aged facial appearance. In cases like this it is very important to correct all the aesthetic defects with a harmonious reposition of the ptotic soft tissues both in the face and in the neck. So in order to obtain a natural result a combined midface lift/lowerface and neck lift should be performed. Thanks to this complete operation, sagging, cheeks, tear troughs, jowls and cervical bands can be corrected.

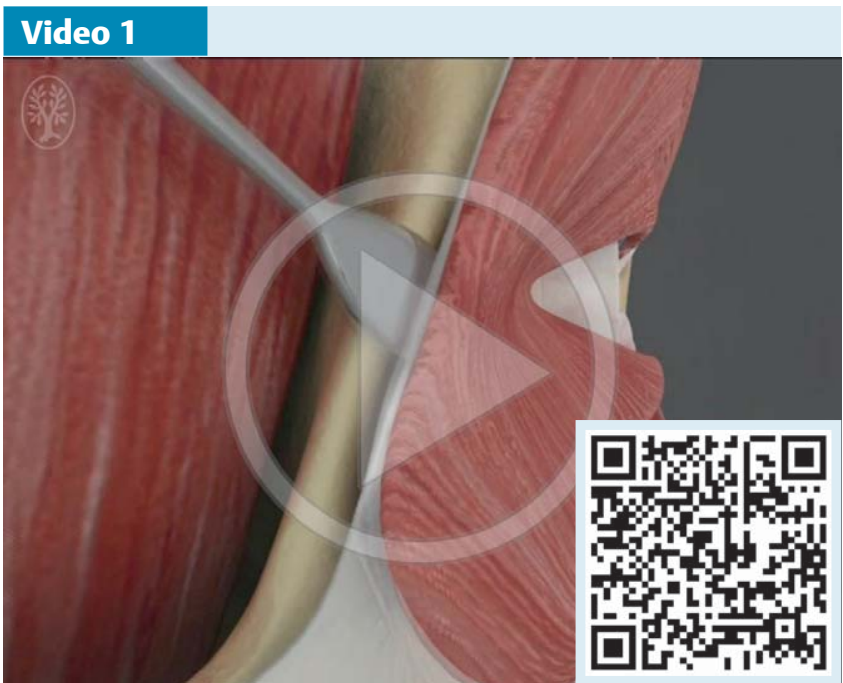

Das Video zu diesem Beitrag finden Sie im Internet unter http://dx.doi.org/10.1055-s-0034-1385927.

created with upmost precision or if the prosthesis is anchored to the bone ( $\bullet$ Fig. 12, 13).

\section{Conclusion}

$\nabla$

Midface lift consists in repositioning malar and maxillary (infrapalpebral) sagging soft tissues. It is indicated when the prevalent defect of this area is soft tissue laxity. If the main problem is atrophy, instead, it is better to resort to some kind of "filling". In many cases it is convenient to reposition soft tissues with a midface lift and correct their atrophy with fat grafting, filler or implants along

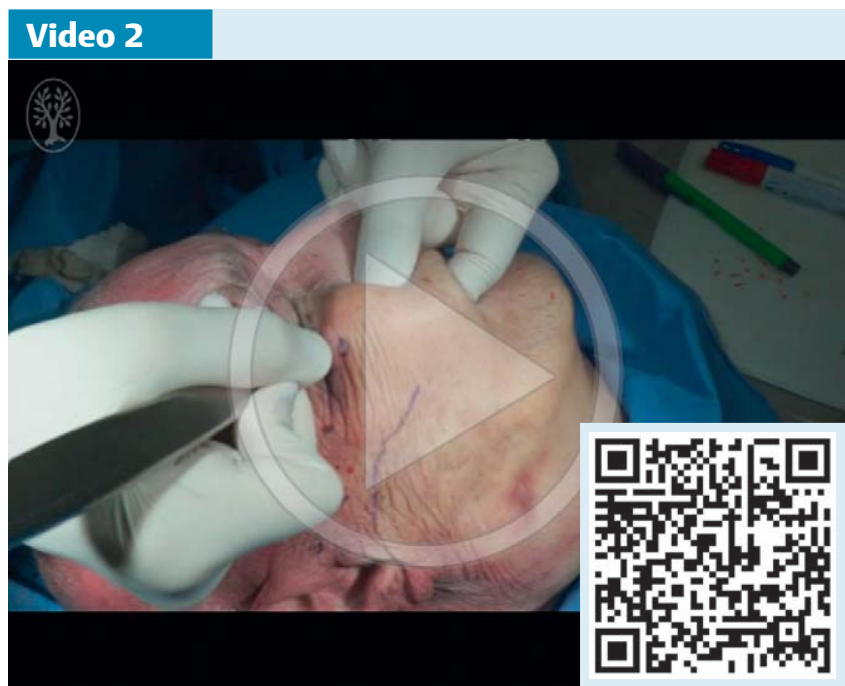

Das Video zu diesem Beitrag finden Sie im Internet unter http://dx.doi.org/10.1055-s-0034-1385927.

the same operation. Fat and fillers can be injected superficially, while implants should be fixed at the bone, eventually through the same drill holes of midface lift, otherwise the wide recipient pocket would allow unwanted movements. We prefer to carry out the midface lift with a sub-periosteal dissection because it allows us to obtain more long-lasting outcomes. Our clinical observations have allowed us to state that the durability of the results is not due to a re-adherence of periosteum to bone in the new uplifted position, but instead to the fact that non-extensible dissected periosteum sticks to non-undermined unchanged one. Midface lift allows us to truly recreate the youthful characteristics lost with ageing, giving back to soft tissues their original position, 


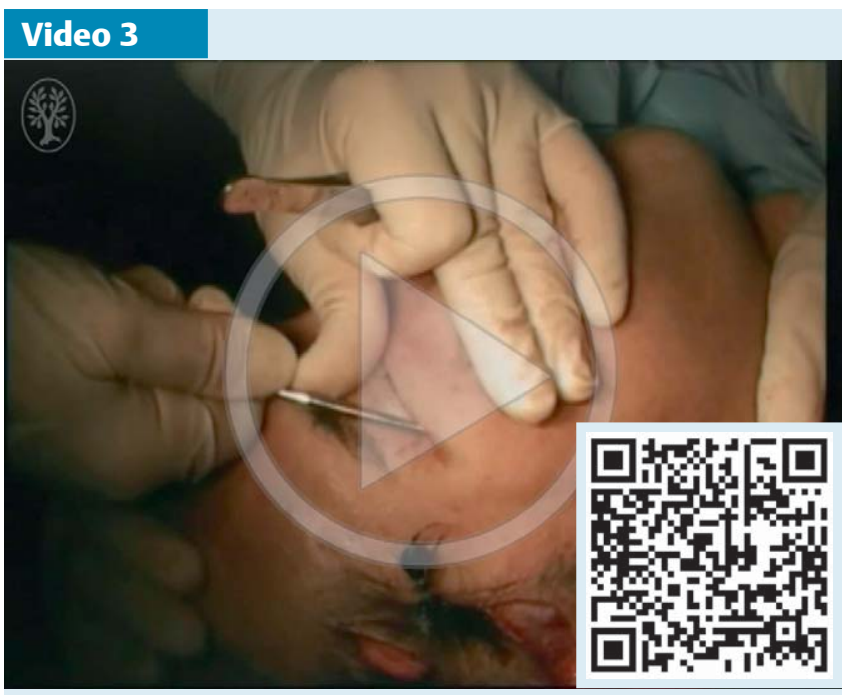

Das Video zu diesem Beitrag finden Sie im Internet unter http://dx.doi.org/10.1055-s-0034-1385927.

volume and shape. Furthermore this operation can be very helpful to treat scleral show and ectropion, in addition to canthoplasties, because it generates a great amount of skin with the same texture and color of the lower lid's lacking one. Generally a midface lift gives excellent, natural and stable results both when is used for aesthetic or functional purposes. But it is not an easy procedure and it takes a steep learning curve to master it.

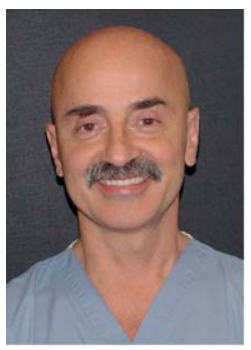

Giovanni Botti

comes from Salò, Lake Garda, Italy and is the head manager and chief surgeon of the Villa Bella Clinic. He took part as faculty member in many aesthetic surgery courses and congresses, organized by both Universities and Scientific Societies in more than 30 different countries. He also performed demonstrative surgical operations in various hospitals worldwide. He is the author of 4 books: "Liposuzione ambulatoriale" (1988), "Chirurgia estetica dell'invecchiamento facciale" ("Aesthetic surgery of the aging face", 1995), "Mastoplastiche estetiche ("Aesthetic mammaplasties”, 2004), “Chirurgia plastica estetica del midface e del collo" ("Midface and neck aesthetic plastic surgery", 2010), translated in English and Spanish, and wrote chapters of several textbooks together with 71 scientific articles published in the most well-known international medical reviews. Dr. Botti was awarded for his contributions to the improvement of Aesthetic Surgery by the American Academy of Cosmetic Surgery (Philadelphia, 1990), by the Japanese Society of Aesthetic Plastic Surgery (Tokyo, 2000), by the Aegiptyan Society of Plastic and Reconstructive Surgery (Cairo, 2001), by IMCAS, (Paris 2003, etc.), by the Romanian Society of Aesthetic, Plastic and Reconstructive Surgery (Sinaia, 2006), by the Moldavian Society of Aesthetic Surgery (2007) and by the Australasian Society of Aesthetic Plastic Surgery (2010). He taught several years at the post-graduate aesthetic plastic surgery class of Pavia University and of Siena University and at the aesthetic surgery Master courses of Milan University. He has been clinical professor of Plastic Surgery at the Verona University from 2002 till now. He has also been lecturer in the Master Courses of Aesthetic Surgery of the Padua University, of the Rome University, of the Genoa University, of the Wien University, of the Nice University and has been the director of the annual Course "Vesalius" on facial plastic surgery (for Italian doctors) of the Bruxelles Free University and of the Course on aesthetic plastic surgery of Villa Bella Clinic. He is honorary member of the French Society of Aesthetic Surgery, of the Aegyptian Society of Plastic, Reconstructive and Aesthetic Surgery, of the Romanian Society of Aesthetic Plastic Surgery, of the Moldavian Society of Aesthetic Plastic Surgery, of the Serbian Society of Plastic, Reconstructive and Aesthetic Surgery and of the Australian Society of Aesthetic Plastic Surgery. He was the first President of the Italian Society of Aesthetic Plastic Surgery (AICPE) and an active member of various national and international societies (AICPE, ISAPS, EASAPS, AFPS, ISLAS, IPRAS etc.). And, perhaps even more important, he loves his job!

\section{Conflict of interest: None.}

\section{References}

1 Adamson JE, McCraw JB, Carraway JH. Use of a muscle flap in lower blepharoplasty. Plast Reconstr Surg 1979; 63: 359-363

2 Adamson PA, Dahiya R, Litner J. Midface Effects of the deep-plane vs the superficial musculoaponeurotic system plication face-lift. Arch Plast Surg 2007; 9: 9-11

3 Alsarraf R, To WC, Johnson CM Jr. The deep plane facelift. Facial Plast Surg 2003; 19: 95-106

4 Barton FE Jr. The SMAS and the nasolabial fold. Plast Reconstr Surg 1992; 89: 1058-1059

5 Besins T. The "R.A.R.E." technique (reverse and repositioning effect): the renaissance of the aging face and neck. Aesthetic Plast Surg 2004; 28: $127-142$

6 Binder WJ, Schoenrock LD, Terino EO. Augmentation of the malarsubmalar/midface. Facial Plast Surg Clin North Am 1994; 2: 265-283

7 Botti G, Pelle Ceravolo M. Midface and Neck Aesthetic Plastic Surgery Vol. I/II. Parma, Italy: Acta Medica Edizioni; 2012

8 Connell BF, Semlacher RA. Contemporary deep layer facial rejuvenation. Plast Reconstr Surg 1997; 100: 1513-1523

9 Cornette de Saint-Cyr B, Garey LJ, Maillard GF et al. The vertical midface lift: an improved procedure. J Plast Reconstr Aesthet Surg 2007; 60: $1277-1286$

10 De la Plaza R, Valiente E, Arroyo JM. Supraperosteal lifting of the upper two-thirds of the face. Br J Plast Surg 1991; 44: 325-332

11 Dempsey $P$, Oneal RM, Izenberg PH. Subperiosteal brow and midface lifts. Aesthetic Plast Surg 1995; 19: 59-68

12 Fuente del Campo A. Cirugia reparadora del envejecimiento facial sin cicatrices visables. Cirugia Cirujanos 1993; 60: 123-132

13 Hamra ST. Composite rhytidectomy. Plast Reconstr Surg 1992; 90: $1-13$

14 Hamra ST. The zygorbicular dissection in composite rhytidectomy: an ideal midface plane. Plast Reconstr Surg 1998; 102: 1646-1657

15 Hinderer UT. The sub-SMAS and subperiosteal rhytidectomy of the forehead and middle third of the face: A new approach to the aging face. Facial Plast Surg 1992; 8: 18-32

16 Isse NG. Endoscopic facial rejuvenation. Clin Plast Surg 1997; 24: 213-231

17 Ivy EJ, Lorenc ZP, Aston SJ. Is there a difference? A prospective study comparing lateral and standard SMAS face lifts with extended SMAS and composite rhytidectomies. Plast Reconstr Surg 1996; 98: 11351147

18 Kamer FM, Mingrone MD. Deep plane rhytidectomy: a personal evolution. Facial Plast Surg Clin North Am 2002; 10: 63-75

19 Krastinova-Lolov D. Le lifting facial sous-perioste. Ann Chir Plast Esthet 1989; 34: 199-211 
20 LaFerriere KA, Kilpatrick JK. Transblepharoplasty: subperiosteal approach to rejuvenation of the aging midface. Facial Plast Surg 2003; 19: $157-170$

21 Le Louarn C, Buthiau D, Buis J. The face recurve concept: medical and surgical applications. Aesthetic Plast Surg 2007; 31: 219-231

22 Le Lourn C. Midface region: functional anatomy, ageing process, indications and concentric malar lift. Ann Chir Plast Esthet 2009; 54: 411-420

23 Little JW. Volumetric perceptions in midface aging with altered priorities for rejuvenation. Plast Reconstr Surg 2000; 105: 252-266

24 McCollough EG, Scurry WC, Shirazi MA. The "midface-lift" as a misnomer for correctly identifying procedures designed to lift and rejuvenate the cheeks and malar regions of the face. Arch Facial Plast Surg 2009; 11: 257-262

25 Newman J. Safety and efficacy of midface-lifts with an absorbable soft tissue suspension device. Arch Plast Surg 2006; 8: 245-251

26 Ortiz-Monasterio F. Aesthetic surgery of the facial skeleton: The forehead. Clin Plast Surg 1991; 18: 19-27

27 Owsley JQ. Lifting the malar fat pad for correction of prominent nasolabial folds. Plast Reconstr Surg 1993; 91: 463-470

28 Paul MD, Calvert JW, Evans GRD. The evolution of the midface lift in aesthetic plastic surgery. Plast Reconstr Surg 2006; 117: 1809-1827
29 Psillakis JM, Rumley TO, Camargos A. Subperiosteal approach as an improved concept for correction of the aging face. Plast Reconstr Surg 1988; 82: 383-394

30 Quatela VC, Jacono AA. The extended centrolateral endoscopic midface lift. Facial Plast Surg 2003; 19: 199-208

31 Ramirez OM, Maillard GF, Musolas A. The extended subperiosteal face lift: a definitive soft-tissue remodeling for facial rejuvenation. Plast Reconstr Surg 1991; 88: 227-236

32 Ramirez OM. Three-dimensional endoscopic midface enhancement: a personal quest for the ideal cheek rejuvenation. Plast Reconstr Surg 2002; 109: 329-349

33 Santana PSM. Metodologia craneomaxilofacial en ritidoplastias. Cirurgia Plastica Ibero-Latino Americana 1984; 10: 321-350

34 Tapia A, Ferreria B, Blanch A. A subperiostic lifting. Aesthetic Plast Surg 1991; 15: 155-160

35 Williams EF III, Vargas H, Dahiya $R$ et al. Midfacial rejuvenation via a minimal incision brow-lift approach. Arch Facial Plast Surg 2003; 5: $470-478$

36 Williams JV. Transblepharoplasty endoscopic subperiosteal mid face lift. Plast Reconstr Surg 2002; 110: 1769-1777 